\title{
Effect of thiazolidinediones on expression of UCP2 and adipocyte markers in human PAZ6 adipocytes
}

\author{
A. Strobel, K. Siquier, V. Zilberfarb, A.D. Strosberg, T. Issad \\ Institut Cochin de Génétique Moléculaire, Paris, France
}

\section{Abstract}

Aims/hypothesis. Thiazolidinediones, a new class of insulin sensitizers, up-regulate the expression of uncoupling protein 2 in rodent adipocytes. It is not known, however, whether thiazolidinediones influence uncoupling protein 2 expression in human adipocytes. We therefore investigated the effect of these drugs on uncoupling protein 2 expression in the recently immortalized human PAZ6 adipocyte cell line. Methods. Immortalized human PAZ6 preadipocytes were differentiated into adipocytes in the presence or absence of thiazolidinediones. The effect of the drugs on uncoupling protein 2 expression and adipocyte differentiation was measured by reverse transcription-polymerase chain reaction of mRNA of uncoupling protein 2 and of five adipocyte differentiation markers.

Results. When cells were differentiated 15 days in the presence of thiazolidinediones, uncoupling protein 2 expression was 2.1-fold higher than in the absence of the drugs. The expression of five adipocyte differentiation markers was, however, also increased by thiazolidinediones. Short-term incubation for 4 and $24 \mathrm{~h}$ with thiazolidinediones increased uncoupling protein 2 expression 1.35 -fold and 2.3-fold, respectively. The expression of adipocyte markers studied in parallel was also augmented.

Conclusion/interpretation. Thiazolidinediones rapidly increase the expression of uncoupling protein 2 in human PAZ6 adipocytes but the increase of uncoupling protein 2 expression is always associated with an augmentation of the expression of all adipocyte markers studied in parallel. This indicates that the effect of thiazolidinediones on uncoupling protein 2 mRNA reflects a general increase in adipocyte differentiation rather than a specific augmentation of uncoupling protein 2 gene expression. [Diabetologia (1999) 42: 527-533]

Keywords Adipocyte, thiazolidinediones, differentiation, uncoupling protein 2 , adipocyte markers, PCR.
Received: 16 October 1998 and in final revised form: 26 November 1998

Corresponding author: T. Issad, Laboratoire d'Immuno-Pharmacologie Moléculaire, CNRS UPR 415, Institut Cochin de Génétique Moléculaire, 22, rue Méchain, F-75014 Paris, France

Abbreviations: $\beta_{3}$-AR, $\beta_{3}$-Adrenergic receptor; HSL, hormone sensitive lipase; LPL, lipoprotein lipase; NTZ, naphthiazo; $\operatorname{PPAR} \gamma$, peroxisome proliferator activated receptor gamma; PPRE, peroxisome proliferator response element; RT, reverse transcription; TZD, thiazolidinedione; UCP, uncoupling protein; aP2, human fatty acid binding protein.
Thiazolidinediones (TZDs) are a new class of insulin sensitizers with the potential to treat Type II (non-insulin-dependent) diabetes mellitus [1, 2]. It has been shown in diabetic humans as well as in rodent models of diabetes that TZDs considerably improve insulin sensitivity by stimulating glucose uptake in peripheral tissues and by inhibiting hepatic gluconeogenesis [3-6]. It is thought that TZDs mainly act by binding to the nuclear transcription factor peroxisome proliferator activated receptor gamma (PPAR $\gamma$ ) and thereby modify the expression of various genes implicated in glucose and lipid metabolism [7]. PPAR $\gamma$ is expressed very early during adipocyte differentiation. Ectopic expression of PPAR $\gamma$ in fibroblasts is suffi- 
cient for their conversion into adipocytes $[8,9]$. Thiazolidinediones are strong promoters of adipocyte differentiation [2]. This has given rise to concern that a possible side-effect of TZDs could be to increase adipose mass in Type II diabetic patients who are often already overweight. In rodents, long-term TZD treatment increases body weight [7]. Moreover, TZDs induce adipose differentiation in rat stromal bone marrow cells which could affect the haematopoetic system and be related to anaemia observed after TZD treatment [10]. Finally, the recent withdrawal of troglitazone from the market in the United Kingdom because of several cases of severe liver failure makes the use of human cells imperative to better evaluate all the effects of these drugs.

Thiazolidinediones also increase the potential for thermogenic energy expenditure in rodents [11] which could be associated with the capacity to up-regulate the expression of uncoupling proteins. Uncoupling proteins are proton conducting proteins of the inner mitochondrial membrane that uncouple the respiratory chain reactions from ATP synthesis [12-17]. These proteins therefore potentially constitute targets for anti-obesity treatments aimed at burning excess fat. Uncoupling protein 1 is restricted to brown adipose tissue, which is lacking in adult humans. Uncoupling protein 2 is expressed in numerous tissues of rodents and humans, including muscle and fat $[15,18,19]$. Recent experiments point to UCP2 having a role in uptake of lipids as fuel substrates rather than in diet-induced thermogenesis [20]. For example, UCP2 is up-regulated in muscle tissue of starving rats and also in animals fed on a high-fat diet compared with animals fed an isocaloric low-fat diet. A positive correlation has been shown between BMI and UCP2 expression in humans [21]. On the other hand, in two rodent models of obesity, no correlation between body weight and UCP2 expression has been observed [22, 23]). In addition, no linkage between $U C P 2$ polymorphisms and Type II diabetes has been found [24-26].

In rodent adipocytes and muscle cell lines, thiazolidinediones can potently upregulate UCP2 but data on modulation of UCP2 expression by TZDs in human adipocytes are not available. We have therefore investigated the effect of thiazolidinediones on UCP2 expression in PAZ6 cells, a recently described immortalized human adipocyte cell line [27].

\section{Materials and methods}

Materials. The thiazolidinediones used were naphthiazo (5-[2(2-naphthylmethyl)-5-benzofuranylmethyl]-2,4-thiazolidinedione) and pioglitazone (5-[4-[2-(5-ethyl-2-pyridyl)ethoxy]benzyl]-2,4-thiazolidinedione). Naphthiazo was a kind gift from Dr. J. Duhault (IRIS, France). Pioglitazone was synthesized according to published protocols [28]. All other chem- icals were purchased from Sigma (Saint Quentin, Fallavier, France) if not otherwise stated and were of the highest purity grade available.

Cell culture of PAZ6 cell line. Throughout this study, immortalized PAZ6 cells [27] have been used. Preadipocytes were cultivated in F-12-DMEM-Ham's medium (1:1 vol/vol, designated as F/D medium) supplemented with $10 \% \mathrm{FCS}$ and $15 \mathrm{mmol} / \mathrm{l}$ HEPES. For differentiation, confluent PAZ6 preadipocytes were cultivated for 2 weeks in F/D medium supplemented with $5 \% \mathrm{FCS}, 0.1 \mu \mathrm{mol} / 1$ dexamethasone, $850 \mathrm{nmol} / 1$ insulin, 1 $\mathrm{nmol} / \mathrm{l}$ triiodothyronine and $1 \mu \mathrm{mol} / \mathrm{l}$ naphthiazo or pioglitazone for 2 weeks. This medium is designated as differentiation medium. The differentiation medium was changed every other day. During the first 4 days of differentiation, 3-isobutyl-1-methyl-xanthine was added (IBMX, $0.25 \mathrm{mmol} / \mathrm{l}$ ). In some experiments, TZDs were removed during the second week of differentiation and re-added for 4 or $24 \mathrm{~h}$ before RNA extraction.

Measurement of intracellular triglyceride content. Adipose conversion was measured by staining intracytoplasmic lipids with Oil red O using a previously published protocol [29].

RNA isolation. Total RNA was extracted from PAZ6 cells using the TRIZOL reagent (Gibco Life Sciences, Cergy, Pontoise, France). From this RNA $20 \mu \mathrm{g}$ were digested with $6 \mathrm{U}$ RNase-free DNase I (RQ1 DNase, Promega, Lyon, France) in $40 \mathrm{mmol} / \mathrm{l}$ TRIS-HCl, $\mathrm{pH} 7.9,10 \mathrm{mmol} / \mathrm{l} \mathrm{NaCl}, 6 \mathrm{mmol} / \mathrm{l}$ $\mathrm{MgCl}_{2}$ and $2 \mathrm{U} / \mathrm{ml}$ RNase inhibitor (RNaseOUT, Gibco Life Sciences). The RNA was extracted with phenol/chloroform, precipitated with ethanol, dried and resuspended in water. Concentrations of RNA were determined photometrically and integrity of total RNA was assessed by agarose electrophoresis. The samples were stored at $-80^{\circ} \mathrm{C}$.

Generation of synthetic RNAs for competitive reverse transcription $R T-P C R$. Synthetic RNA competitors were designed to be amplified in RT-PCR with the same primers that were used for the RT-PCR of UCP2 or aP2 mRNAs, but giving PCR-products differing in size from the endogenous reverse transcribed mRNAs. These synthetic RNA competitors for quantification of UCP2 and aP2 mRNAs were generated by RT-PCR of PAZ6 RNA using composite primers as described [30] and the Ribomax RNA-synthesis kit (Promega). Sense composite primers specific for the $U C P 2$ or $a P 2$ gene contained the T7-RNA-polymerase universal promotor at their $5^{\prime}$ end allowing for transcription of the PCR-products into RNA. Antisense composite primers contained at their $5^{\prime}$ moiety the UCP2 or aP2 antisense primers described in the paragraph "RT-PCR", but annealed with their 3 ' moiety more upstream.

UCP2: sense $5^{\prime}$ TAATACGACTCACTATAGGGGATGTGCTGAGCTGGTGACCTATGA3' composite antisense: 5'AAGGGAGCCTCTCGGGAAGTGCAGTTCCAGGAACCCAAGCGGAGAGGG3'

aP2: sense 5 "TAATACGACTCACTATAGGGGATCCAGTGAAAACTTTGATGATTAT3' composite antisense: 5 'ACGCATTCCACCACCAGTTATCAATTTCTGCACATGTACCAGGACAC3'

$R T$-PCR. cDNA was synthesized from $200 \mathrm{ng}$ DNA-free total RNA using Moloney murine leukemia virus reverse transcriptase (Superscript II Plus, Gibco Life Sciences) according to the manufacturer's protocol. For quantitative competitive RT-PCR analysis of gene expression, PAZ6 total RNA was reverse transcribed in the presence of known amounts of syn- 
thetic competitor RNA. Controls without reverse transcriptase were done in order to exclude DNA contamination. We amplified 50-400 ng of reverse-transcribed RNA with 1.5 U Taq Polymerase (Gibco Life Sciences) in $50 \mu \mathrm{l}$ containing $20 \mathrm{mmol} / \mathrm{l}$ TRIS-HCl, pH $8.0,50 \mathrm{mmol} / 1 \mathrm{KCl}, 1,5 \mathrm{mmol} / \mathrm{l}$ $\mathrm{MgCl}_{2}, 250 \mu \mathrm{mol} / 1 \mathrm{dNTP}$ and $250 \mu \mathrm{mol} / \mathrm{l}$ of gene-specific sense-primers and antisense-primers in a temperature cycler (GeneAmp PCR System 9600, Perkin-Elmer Cetus, Courtaboeuf, France). The PCR-products were made visible on $2 \%$ agarose gels by ethidium bromide staining. The PCRband intensities were analysed by densitometric scanning. For all semi-quantitative RT-PCRs, analysis of mRNA expression was carried out during the exponential phase of the amplification. The exponential phase of each RT-PCR was determined by titrations of cycle numbers and quantities of total RNA.

Primers for the following mRNAs were designed with the program Oligo4 using the following Genbank entries:

UCP2 (Acc. number U76367): sense 5 'TGTGCTGAGCTGGTGACCTATGAC3 ${ }^{\prime}, 5^{\prime}$ annealing position 571; antisense 5 'AAGGGAGCCTCTCGGGAAGTGCAG3', 5' annealing position 926

aP2 (Acc. number J02874): sense 5 "TCCAGTGAAAACTTTGATGATTAT3', 5' annealing position 99; antisense 5 'ACGCATTCCACCACCAGTTTATCA3', 5' annealing position 418

PPAR $\gamma$ (Acc. number L40 904): sense 5'AGACAACAGACAAATCACCAT3 ', 5' annealing position 894; antisense 5 'CTTCACAGCAAACTCAAACTT3', 5' annealing position 1294

cyclophilin (Acc. number Y00052): sense 5'AGCACTGGAGAGAAAGGATT3', 5' annealing position 132; antisense 5 'GGAGGGAACAAGGAAAACAT3', 5 ' annealing position 659

LPL (Acc. number M76722): sense 5'GAGATTTCTCTGTATGGCACC3', 5' annealing position 267; antisense 5 'CTGCAAATGAGACACTTTCTC3', 5' annealing position 3091

$\boldsymbol{\beta}_{3}$-adrenergic receptor (Acc. number X72861): sense 5'CCCAATACCGCCAACAACAGT3', antisense, 5' annealing position 701 ; 5'CGACCCACACCAGGACCA$\mathrm{CAG}^{\prime}, 5^{\prime}$ annealing position 1127

hormone sensitive lipase (Acc. number L11706): sense 5'GGGGCTGAGTTTGAGCG3', 5' annealing position 1298; antisense 5'GCTCCTCACTGTCCTGTCC3', 5' annealing position 1583

Statistical analysis. Data were analysed using Student's $t$ test for unpaired data.

\section{Results}

Differentiation of PAZ6 cells and expression of Uncoupling Protein 2. In preliminary experiments, we determined that a 2 -week period of exposure to a standard differentiation medium was optimal for differentiation of the PAZ6 cells, as judged by expression of adipocyte markers (not shown). Here we assessed the extent of differentiation of these cells in more detail by semi-quantitative RT-PCR of the mRNAs of the adipocyte markers lipoprotein lipase (LPL), $\beta_{3}$-adrenergic receptor $\left(\beta_{3}\right.$-AR), hormone sensitive lipase (HSL), human fatty acid binding protein $(\mathrm{aP} 2)$, and peroxisome proliferator activated re- differentiation

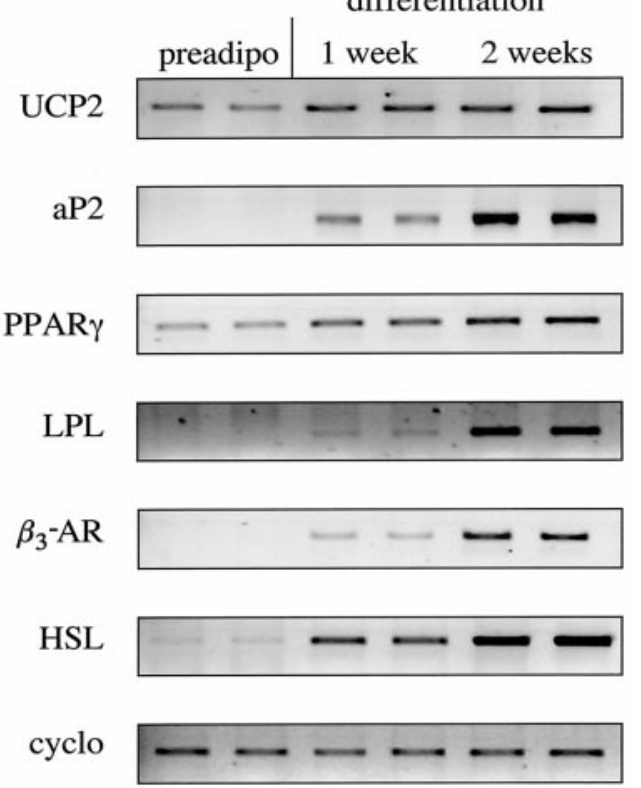

Fig. 1. Expression of adipocyte markers during differentiation of PAZ6 cells. Cells were differentiated as described in Materials and methods. For each point in time, semi-quantitative RTPCR was carried out in duplicate. PCR products were made visible on agarose gels by ethidium bromide staining. As a control, the signals for cyclophilin expression are also shown. The results are representative of four independent experiments done in duplicate

ceptor $\gamma(\operatorname{PPAR} \gamma)$. Total RNAs were isolated from confluent preadipocytes $(\mathrm{t}=0$ of differentiation) and after 1 and 2 weeks of differentiation. The expression of these genes increases as the PAZ6 cells acquire the phenotype of mature adipocytes (Fig. 1).

Recently, UCP2, a homologue of the brown adipocyte-specific uncoupling protein 1 (UCP1), has been cloned $[15,16]$. The expression pattern of UCP2 in human adipocytes during differentiation is not known. We therefore examined the expression of UCP2 in differentiating PAZ6 cells by semi-quantitative RT-PCR. We found that UCP2 mRNA is already present in preadipocytes at confluence (beginning of the differentiation protocol) (Fig.1). After 1 week of differentiation, the mRNA expression rose twofold and were 2.7-fold higher at day 14 of differentiation than at day 0 , showing that, as described for rodent adipocytes [31], UCP2 mRNA expression increases during differentiation of human adipocytes.

Effect of thiazolidinediones on UCP2 expression and PAZ6 differentiation. In a first set of experiments, we investigated the long-term effect of TZDs on UCP2 expression in PAZ6 cells. Simultaneously, we examined how these drugs influence the differentiation state of the cells. We assessed the long-term effect of two different TZDs, naphthiazo and pioglitazone, on UCP2 expression in human PAZ6 cells (Fig. 2a). Compared with cell differentiated in a me- 
a

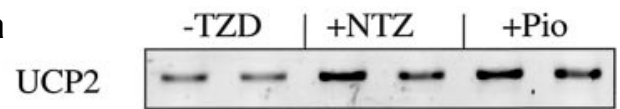

aP2

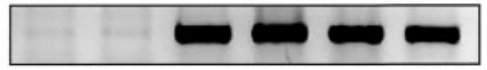

$\operatorname{PPAR} \gamma$

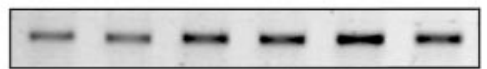

LPL

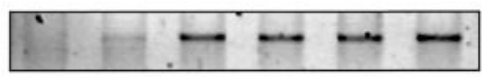

$\beta_{3}$-AR

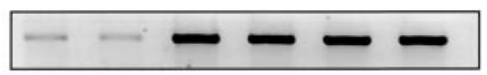

HSL

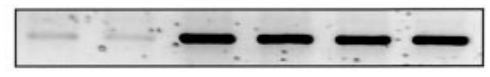

cyclo

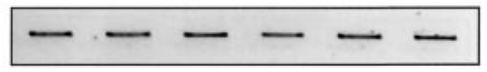

b

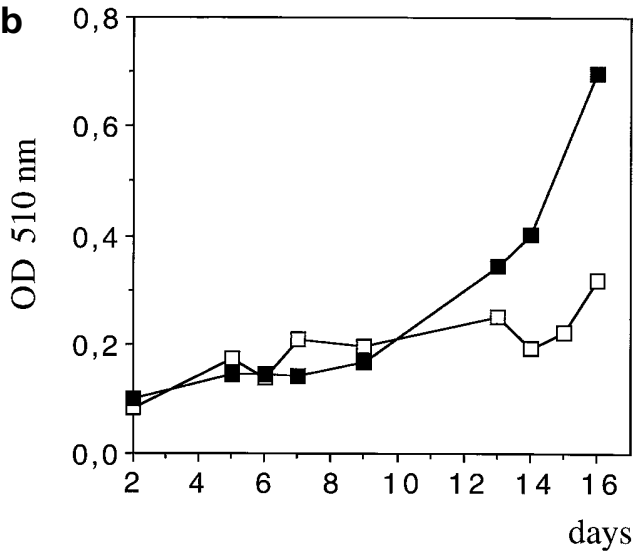

Fig.2.a, b Long-term effects of TZDs on the differentiation of PAZ6 cells. a Gene expression in cells exposed or not to TZDs during differentiation was assessed by semi-quantitative RTPCR. The results are representative of three independent experiments done in duplicate. b Effect of naphthiazo (NTZ) on triglyceride accumulation. PAZ6 cells were differentiated in the absence $(\square)$ or in the presence $(\square)$ of NTZ. At various points in time during differentiation, cells were stained with Oil red for intracellular triglyderides. Triglyceride content was measured photometrically at $510 \times 10^{-9} \mathrm{~m}$. Pio, pioglitazone

dium lacking TZDs, UCP2 expression was about 2.1fold higher in adipocytes differentiated in the presence of $1 \mu \mathrm{mol} / \mathrm{l} \mathrm{TZD}$. Examination of the mRNA expressions of the other genes studied shows that both TZDs have also a profound effect on the differentiation of the cells. Cells incubated for 2 weeks with a differentiation medium lacking TZDs barely express aP2 and LPL mRNAs, and $\beta_{3}$-AR and HSL are expressed at low levels compared with cells that were exposed for 2 weeks to naphthiazo or pioglitazone. The influence of TZDs on adipocyte differentia-

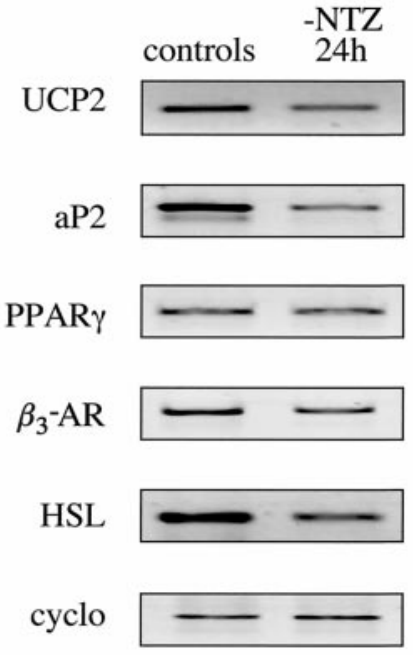

Fig.3. Expression of adipocyte-associated genes after removal of naphthiazo (NTZ). PAZ6 cells were differentiated with the differentiation cocktail containing NTZ as described in Materials and methods. NTZ was removed from the medium $24 \mathrm{~h}$ before RNA extraction

tion was also measured by staining of intracellular triglycerides, which accumulate during differentiation. We plotted triglyceride content of PAZ6 cells differentiated in the absence or presence of naphthiazo compared with the time of differentiation (Fig. 2b). After 15 days of differentiation, lipid accumulation was about twofold higher in cells differentiated in the presence of naphthiazo. Altogether, these results show that long-term incubation of PAZ6 cells with TZDs increases UCP2 expression but also the differentiation state of the cells as judged by triglyceride content and the expression of differentiation markers. It is thus not possible to conclude from this experiment that TZDs specifically alter UCP2 expression.

To investigate the role of TZDs in UCP2 expression in adipocytes differentiated to a maximum, cells were differentiated for 2 weeks in the presence of TZDs. We replaced the differentiation medium by the same medium but lacking TZD $24 \mathrm{~h}$ before RNA extraction. Removal of TZDs considerably reduced aP2 and UCP2 expression, but also that of all the other adipocyte markers we tested (Fig.3). Again, it was not possible to dissociate the effect on UCP2 expression from the effect on the differentiation state of the cells. Apparently, even terminally differentiated PAZ6 cells need the continous presence of TZDs to maintain a maximum differentiated phenotype.

We next investigated UCP2 expression in PAZ6 cells upon short-term exposure to TZDs. Cells were differentiated for the first week in the presence of either naphthiazo or pioglitazone. In the second week, cells were differentiated in the same differentiation medium but lacking TZDs. Cells were then incubated or not with TZDs for $24 \mathrm{~h}$. Treatment with naphthiazo for $24 \mathrm{~h}$ increased UCP2 expression by 
$\mathbf{a}$
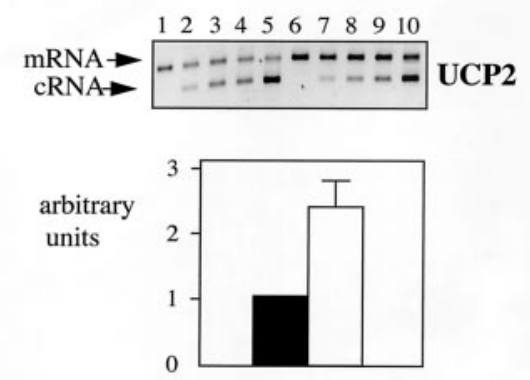

b

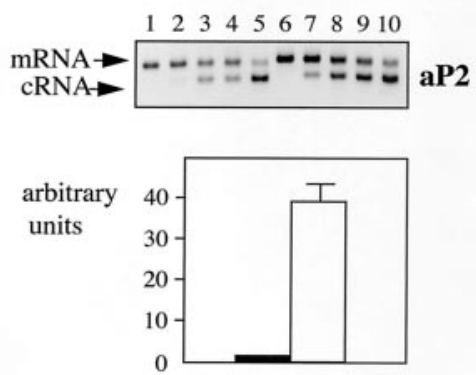

Fig.4.a, b Quantitative RT-PCR measurement of the effect of naphthiazo (NTZ) on UCP2 a and aP2 expression b in PAZ6 adipocytes. The upper bands correspond to the signals given by the cellular mRNAs, the lower bands correspond to the signals given by the synthetic competitor RNA. UCP2 and aP2 mRNAs were quantified as described [44]. Lanes 1-5: control mRNA. Lanes 6-10: mRNA of cells incubated for $24 \mathrm{~h}$ with NTZ. Lanes 2-5 and 7-10 contain increasing amounts of competitor RNA. a Representative gel of competitive RTPCRs for UCP2. $100 \mathrm{ng}$ of cellular total RNA are amplified in each lane. b Effect of NTZ on aP2 expression. Because of the large difference in aP2 expression in untreated and treated cells, $400 \mathrm{ng}$ of total RNA from control cells are amplified in lanes $1-5$ but only $100 \mathrm{ng}$ of total RNA from NTZ-treated cells are amplified in lanes $6-10$. The effect of NTZ on UCP2 and aP2 expression is given as the means \pm SEM of three independent experiments. Black bars: control. White bars: + NTZ. The value 1 was arbitrarily assigned to UCP2 and aP2 expression in control cells. UCP2 and aP2 mRNA in NTZ-treated cells are expressed relative to the value in control cells

$2.3 \pm 0.78$-fold, $(n=3, p<0.05)$ but naphthiazo increased aP2 expression by about 40 -fold (Fig. 4). Incubation of PAZ6 cells with TZDs for $24 \mathrm{~h}$ increased the expression of all the adipocyte differentiation markers we tested (Fig. 5).

Finally, to determine whether a shorter stimulation would show kinetic differences between UCP2 expression and the expression of other markers, we repeated the experiment shown in Figure 5, reducing the time of incubation with TZDs to $4 \mathrm{~h}$. Quantitative RT-PCR measurements carried out as described in Figure 3 showed that 4 -h incubation with naphthiazo increased UCP2 expression $1.350 \pm 0.014$-fold $(n=3$, $p<0.003)$. The expression of all markers studied are depicted (Fig. 6). As in Figure 4, all markers with the

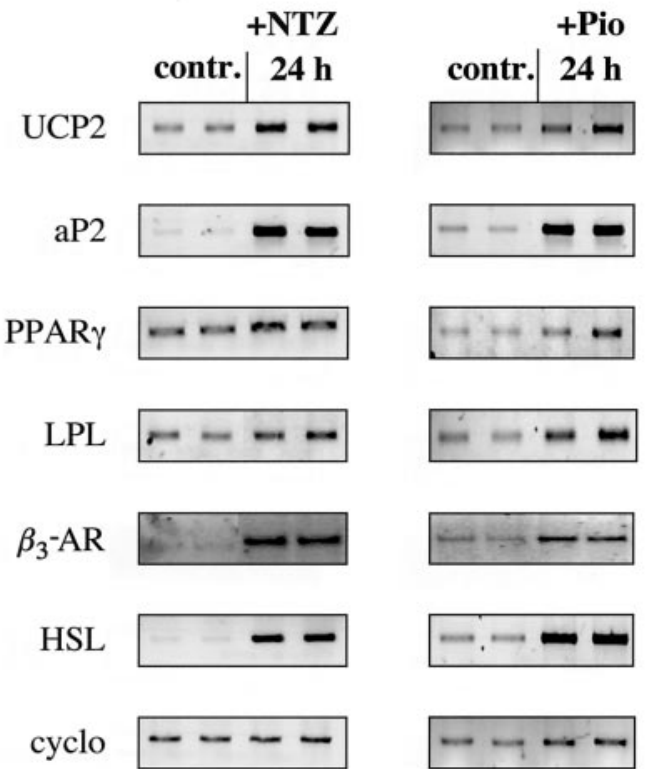

Fig. 5. Semi-quantitative RT-PCR analysis of the expression of adipocyte markers in PAZ6 cells upon $24 \mathrm{~h}$ of TZD stimulation. Cell culture protocols were as in Figure 4. Results are shown in duplicate and are representative of four independent experiments. Pio, pioglitazone

exception of $\operatorname{PPAR} \gamma$, were augmented after $4 \mathrm{~h}$ of TZD treatment.

These results suggest that even for very short incubations, the effect of TZDs on UCP2 expression cannot be distinguished from the effect of these drugs on other adipocyte differentiation markers. The augmentation of UCP2 by TZDs appears to be a mere consequence of the differentiation promoting action of these drugs.

\section{Discussion}

In this study, we have reported the expression of several adipocyte markers in human adipocytes during differentiation. Virtually no expression is detectable for the $\beta_{3}-A R, H S L$ and $a P 2$ genes in confluent PAZ6 preadipocytes. These proteins are involved in lipid metabolism or storage or both. Adipocytes acquire the enzymes for lipid storage and mobilization, such as HSL, $\beta_{3}$ - AR and $\mathrm{aP} 2$, late during the differentiation process [32]. In particular, $\beta_{3}$-AR and HSL are considered to be late markers of adipocyte differentiation [33, 32] whereas LPL is an exception and is thought to be an early marker expressed at confluence in rodent adipocytes [34]. We observed that expression of LPL was very weak in confluent preadipocytes and continued to augment during the whole differentiation process. This difference in the expression pattern of LPL between PAZ6 cells and rodent cells could be due to species-specific differences. In agreement with our results, LPL activity measured 


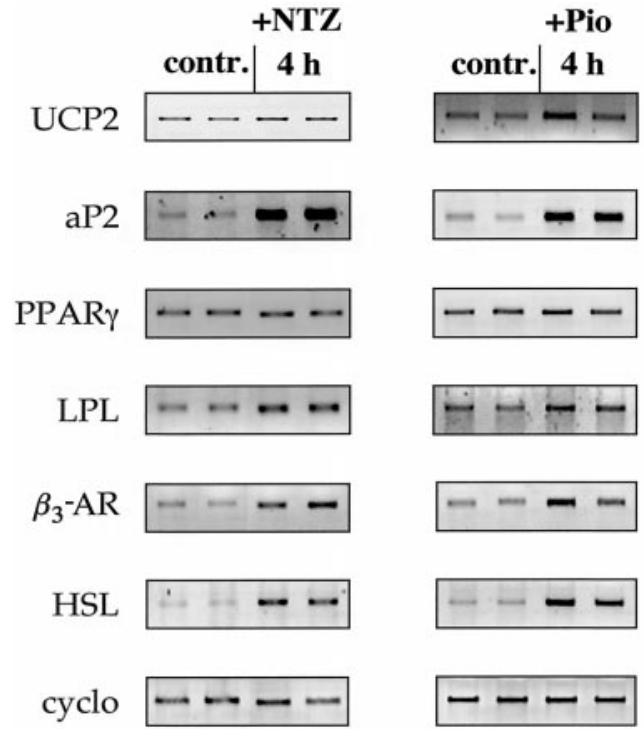

Fig. 6. Semi-quantitative RT-PCR analysis of the expression of adipocyte-associated genes in PAZ6 cells upon $4 \mathrm{~h}$ of TZD stimulation. Experimental conditions were as in Figure 5 but cells were incubated with TZDs for only $4 \mathrm{~h}$. Results are shown in duplicate and are representative of three independent experiments. Pio, pioglitazone

during differentiation in primary cultures of human adipocytes has been shown to reach its maximum only after 2 weeks of differentiation [35].

We further showed that PPAR $\gamma$ is already expressed in confluent preadipocytes. As shown in rodents [36], PPAR $\gamma$ is therefore an early differentiation marker in human PAZ6 adipocytes. This is in line with its role as a master transcription factor regulating adipocyte differentiation. Its increase during 2 weeks of differentiation (1.5-fold) is not as pronounced as for aP2, HSL, $\beta_{3}$-AR or LPL.

The effect of TZDs on rodent adipocyte differentiation has been studied extensively. In human adipocytes the effect of troglitazone on adipocyte differentiation has been quantified by measuring glycerol-3phophate dehydrogenase activity [37]. There is, however, no detailed analysis of the effect of these drugs on the expression of differentiation markers in human adipocytes. We have reported here the effect of TZDs on the expression of several genes in human PAZ6 adipocytes. In line with previous reports on rodent adipocytes [38, 7], we show that TZDs strongly increase the expression of several adipocyte markers.

Two studies describe the stimulation of UCP2 expression by TZDs and PPAR $\gamma$ activators in rodent cell lines but the possibility that these effects could be due to a general increase in the differentiation state of the cells has not been examined. Murine adipocytes have been incubated at confluence for various times with TZDs but the expression of differentiation markers was not measured [39]. An increase of UCP2 expression in differentiated Ob1771 cells during short- term treatment with troglitazone, which is accompanied by an increase in the murine $a P 2$ gene expression has been shown [31]. Since this latter gene is, however, known to possess a peroxisome proliferator responsive element (PPRE) and to be rapidly induced by TZDs, it cannot be determined from this study whether short-term incubation with TZDs specifically upregulates $\mathrm{UCP} 2$ and $\mathrm{aP} 2$ expression or whether it affects the general differentiation state of the cell.

In this study, we also assessed the influence of short-term incubation with TZDs on the expression of the $U C P 2$ gene. After 4- or 24-h exposure of PAZ6 cells to TZDs, the TZD-induced increase in UCP2 expression was accompanied by a rise in most of the differentiation markers studied. The genes for $L P L$ and $a P 2$ both possess a functional PPRE in their promoters $[40,41]$ and have been shown to be directly activated by liganded PPAR $\gamma$. In contrast, the promoters of the $H S L$ and $\beta_{3}-A R$ genes have not so far been reported to contain a PPRE $[42,43]$. The up-regulation of the mRNAs for $\beta_{3}$-AR and HSL within $4 \mathrm{~h}$ of TZDs exposure, points to the possibility that even indirect consequences of TZDs action occur rapidly.

In conclusion, we have shown that TZDs stimulate UCP2 expression in human adipocytes but that TZDs also rapidly augment the expression of various adipocyte markers. The up-regulation of UCP2 mRNA could be the result of an increased differentiation of the cell rather than a specific effect on $U C P 2$ gene expression.

Acknowledgements. We are very grateful to Dr. R. Jockers for useful advice on competitive RT-PCR methodology and to Dr. J. Duhault from the Institut de Recherches Servier (IRIS) for kindly providing us with naphthiazo. This work was supported by the Fondation de France, the CNRS, IRIS and the Université Paris VII. A. Strobel is a Marie Curie Fellow of the European Union (grant number ERBFMBICT960 924).

\section{References}

1. Saltiel AR, Olefsky JM (1996) Thiazolidinediones in the treatment of insulin resistance and type II diabetes. Diabetes 45: 1661-1669

2. Spiegelman BM (1998) PPAR-gamma: adipogenic regulator and thiazolidinedione receptor. Diabetes 47: 507-514

3. Suter SL, Nolan JJ, Wallace P et al. (1992) Metabolic effects of new oral hypoglycemic agent CS-045 in NIDDM subjects. Diabetes Care 15: 193-203

4. Chaiken RL, Eckert-Norton M, Pasmantier R et al. (1995) Metabolic effects of darglitazone, an insulin sensitizer, in NIDDM subjects. Diabetologia 38: 1307-1312

5. Stevenson RW, Hutson NJ, Krupp MN et al. (1990) Actions of novel antidiabetic agent englitazone in hyperglycemic hyperinsulinemic ob/ob mice. Diabetes 39: 1218-1227

6. Sreenan S, Sturis J, Pugh Wet al. (1996) Prevention of hyperglycemia in the Zucker diabetic fatty rat by treatment with metformin or troglitazone. Am J Physiol 271:E742-E747

7. Hallakou S, Doare L, Foufelle F et al. (1997) Pioglitazone induces in vivo adipocyte differentiation in the obese Zucker fa/fa rat. Diabetes 46: 1393-1399 
8. Brun RP, Tontonoz P, Forman BM et al. (1996) Differential activation of adipogenesis by multiple PPAR isoforms. Genes Dev 10: 974-984

9. Tontonoz P, Hu E, Graves RA et al. (1994) mPPAR gamma 2: tissue-specific regulator of an adipocyte enhancer. Genes Dev 8: 1224-1234

10. Gimble JM, Robinson CE, Wu X et al. (1996) Peroxisome proliferator-activated receptor-gamma activation by thiazolidinediones induces adipogenesis in bone marrow stromal cells. Mol Pharmacol 50: 1087-1094

11. Rothwell NJ, Stock MJ, Tedstone AE (1987) Effects of ciglitazone on energy balance, thermogenesis and brown fat activity in the rat. Mol Cell Endocrinol 51: 253-257

12. Klingenberg M (1990) Mechanism and evolution of the uncoupling protein of brown adipose tissue. Trends Biochem Sci 15: 108-112

13. Himms-Hagen J (1990) Brown adipose tissue thermogenesis: interdisciplinary studies. FASEB J 4: 2890-2898

14. Ricquier D, Casteilla L, Bouillaud F (1991) Molecular studies of the uncoupling protein. FASEB J 5: 2237-2242

15. Fleury C, Neverova M, Collins S et al. (1997) Uncoupling protein-2: a novel gene linked to obesity and hyperinsulinemia. Nat Genet 15: 269-272

16. Gimeno RE, Dembski M, Weng X et al. (1997) Cloning and characterization of an uncoupling protein homolog: a potential molecular mediator of human thermogenesis. Diabetes 46: 900-906

17. Boss O, Samec S, Kuhne F et al. (1998) Uncoupling protein-3 expression in rodent skeletal muscle is modulated by food intake but not by changes in environmental temperature. J Biol Chem 273: 5-8

18. Boss O, Samec S, Paoloni-Giacobino A et al. (1997) Uncoupling protein-3: a new member of the mitochondrial carrier family with tissue-specific expression. FEBS Lett 408: 39-42

19. Vidal-Puig A, Solanes G, Grujic D et al. (1997) UCP3: an uncoupling protein homologue expressed preferentially and abundantly in skeletal muscle and brown adipose tissue. Biochem Biophys Res Commun 235: 79-82

20. Samec S, Seydoux J, Dulloo AG (1998) Role of UCP homologues in skeletal muscles and brown adipose tissue: mediators of thermogenesis or regulators of lipids as fuel substrate? FASEB J 12: 715-724

21. Millet L, Vidal H, Andreelli F et al. (1997) Increased uncoupling protein-2 and -3 mRNA expression during fasting in obese and lean humans. J Clin Invest 100: 2665-2670

22. Strobel A, Combettes-Souverain M, Doaré L et al. (1998) Rat UCP2: expression in VMH-lesioned animals. Int J Obes Relat Metab Disord 22: 1121-1126

23. Hidaka S, Kakuma T, Yoshimatsu H et al. (1998) Molecular cloning of rat uncoupling protein $2 \mathrm{cDNA}$ and its expression in genetically obese Zucker fatty (fa/fa) rats. Biochim Biophys Acta 1389: 178-186

24. Otabe S, Clement K, Rich N et al. (1998) Mutation screening of the human UCP 2 gene in normoglycemic and NIDDM morbidly obese patients: lack of association between new UCP 2 polymorphisms and obesity in French Caucasians. Diabetes 47: 840-842

25. Kubota T, Mori H, Tamori Y et al. (1998) Molecular screening of uncoupling protein 2 gene in patients with noninsulin-dependent diabetes mellitus or obesity. J Clin Endocrinol Metab 83: 2800-2804

26. Urhammer SA, Dalgaard LT, Sorensen TI et al. (1997) Mutational analysis of the coding region of the uncoupling protein 2 gene in obese NIDDM patients: impact of a common amino acid polymorphism on juvenile and maturity onset forms of obesity and insulin resistance. Diabetologia 40: $1227-1230$
27. Zilberfarb V, Piétri-Rouxel F, Jockers R et al. (1997) Human immortalized brown adipocytes express functional $\beta_{3^{-}}$ adrenoceptor coupled to lipolysis. J Cell Sci 110: 801-807

28. Momose Y, Meguro K, Ikeda H et al. (1991) Studies on antidiabetic agents. X. Synthesis and biological activities of pioglitazone and related compounds. Chem Pharm Bull (Tokyo) 39: 1440-1445

29. Ramirez-Zacarias JL, Castro-Munozledo F, Kuri-Harcuch W (1992) Quantitation of adipose conversion and triglycerides by staining intracytoplasmic lipids with Oil red O. Histochemistry 97: 493-497

30. Zhang J, Desai M, Ozanne SE et al. (1997) Two variants of quantitative reverse transcriptase PCR used to show differential expression of alpha-, beta- and gamma-fibrinogen genes in rat liver lobes. Biochem J 321: 769-775

31. Aubert J, Champigny O, Saint-Marc P et al. (1997) Up-regulation of UCP-2 gene expression by PPAR agonists in preadipose and adipose cells. Biochem Biophys Res Commun 238: 606-611

32. Cornelius P, MacDougald OA, Lane MD (1994) Regulation of adipocyte development. Annu Rev Nutr 14: 99-129

33. El Hadri K, Feve B, Pairault J (1996) Developmental expression and functional activity of beta 1- and beta 3adrenoceptors in murine 3T3-F442A differentiating adipocytes. Eur J Pharmacol 297: 107-119

34. MacDougald OA, Lane MD (1995) Transcriptional regulation of gene expression during adipocyte differentiation. Annu Rev Biochem 64: 345-373

35. Hauner H, Entenmann G, Wabitsch M et al. (1989) Promoting effect of glucocorticoids on the differentiation of human adipocyte precursor cells cultured in a chemically defined medium. J Clin Invest 84: 1663-1670

36. Zhang B, Berger J, Hu E et al. (1996) Negative regulation of peroxisome proliferator-activated receptor-gamma gene expression contributes to the antiadipogenic effects of tumor necrosis factor-alpha. Mol Endocrinol 10: 1457-1466

37. Adams M, Montague CT, Prins JB et al. (1997) Activators of peroxisome proliferator-activated receptor gamma have depot-specific effects on human preadipocyte differentiation. J Clin Invest 100: 3149-3153

38. Kletzien RF, Clarke SD, Ulrich RG (1992) Enhancement of adipocyte differentiation by an insulin-sensitizing agent. Mol Pharmacol 41: 393-398

39. Camirand A, Marie V, Rabelo R et al. (1998) Thiazolidinediones stimulate uncoupling protein-2 expression in cell lines representing white and brown adipose tissues and skeletal muscle. Endocrinology 139: 428-431

40. Harris PK, Kletzien RF (1994) Localization of a pioglitazone response element in the adipocyte fatty acid-binding protein gene. Mol Pharmacol 45: 439-445

41. Schoonjans K, Peinado-Onsurbe J, Lefebvre AM et al. (1996) PPARalpha and PPARgamma activators direct a distinct tissue-specific transcriptional response via a PPRE in the lipoprotein lipase gene. EMBO J 15: 5336-5348

42. van Spronsen A, Nahmias C, Krief S et al. (1993) The promoter and intron/exon structure of the human and mouse beta 3-adrenergic-receptor genes. Eur J Biochem 213: $1117-1124$

43. Grober J, Laurell H, Blaise R et al. (1997) Characterization of the promoter of human adipocyte hormone-sensitive lipase. Biochem J 328: 453-461

44. Roulot D, Durand H, Coste T et al. (1995) Quantitative analysis of transforming growth factor beta 1 messenger RNA in the liver of patients with chronic hepatitis C: absence of correlation between high levels and severity of disease. Hepatology 21: 298-304 